\title{
The Technology of Activation of Theoretical and Creative Thinking of Bilingual Students
}

\author{
Valerian F. Gabdulchakov ${ }^{1}$ \\ ${ }^{1}$ Kazan (Volga region) Federal University, Kazan, Russia \\ Correspondence: Valerian F. Gabdulchakov, Kazan (Volga region) Federal University, Kremlyovskaya Street 18, \\ Kazan, 420008, Russia. E-mail: progabdulhakov@gmail.com
}

Received: January 19, 2014

Accepted: February 22, 2015 Online Published: March 24, 2015

doi:10.5539/res.v7n5p72

URL: http://dx.doi.org/10.5539/res.v7n5p72

\begin{abstract}
Bilingual students constitute a significant part of the school students in Russia. The main problem of their education quality is digesting the general educational subjects (especially mathematics and physics) in Russian, which is the second language for them. The purpose of the article is detecting the reasons of poor effectiveness of mathematics and physics lessons and developing the technology which will be able to improve the level of acquiring knowledge in these subjects. The main methods of the research were analytical, diagnostic and experimental. The results of the research showed that mathematics and physics teachers disregard activation and development of the students' creative thinking at their classes. On the basis of data received the article presents the technology of theoretical and creative thinking activation. The technology essentially increases the quality of education, the level of theoretical thinking and creativeness development among 5-11 year students in mathematics and physics classes. The article may be of interest to school and university teachers.
\end{abstract}

Keywords: bilingual student, mathematics and physics classes, theoretical and practical thinking, creative thinking, students' creative abilities

\section{Introduction}

\subsection{Actualizing the Problem}

Learning efficiency is normally related to the quality of education. The Strategy of long-term social and economic development of Russia until 2020 emphasizes that quality education must be personalized, continuous, related to world science and oriented to forming a creative and socially responsible individual (2008). Thus in Russia the quality of education is understood to be the level of a student's success, socialization and the level of acquiring knowledge according to educational programs. The results, providing high quality level, are academic knowledge, social and other competences and social experience gained by a student in the course of study (Sakhievaet al., 2015; Ivanenkoet al., 2015; Torkunovaet al., 2014; Shaidullina et al., 2015; Kalimullin \& Gabdilkhakov, 2014; Vlasova et al., 2015). Knowledge, competences and social experience are related to the student's thinking, both reproductive and creative. That is why most teachers while developing reproductive thinking, also do their best to make it creative. But, if a student thinks in his native language (Tatar, Chuvash, Mari etc.) but gets knowledge in another language (his second language, Russian), then all the teachers' attempts in developing his creative thinking in the second language may be useless (Ivanov et al., 2015; Lisitzina et al., 2015; Levina et al., 2015; Valeeva et al., 2015).

\subsection{Explore Importance of the Problem}

It is known that in psychology the term "thinking" is understood as a combination of mental processes, providing the world cognition. Thinking includes active cognition: concentration, perception, associations, concept and estimate formation. We have already studied the influence of thinking on speech development (Gabdulchakov, 2011, 2014-a, b, c; Valeeva \& Valeeva, 2013; Biktagirova \& Valeeva, 2014). How does thinking affect creativity?

For educators it is important that according to Rubinstein (1989) thinking is related to creating perceptions and conclusions based on activating different thinking operations during the classes: 1) the analysis related to dividing a thing into components; 2) synthesis, which allows uniting the links, separated while analyzing; 3 ) comparison, that is correlating things and events, finding their similarities and differences; 4) classification, related to organizing the things by characteristics; 5) generalization, which allows uniting the things according to 
their common essential features; 6) concretizing, which assumes defining details in general; 7) abstracting, which allows defining one aspect of a thing or an event and ignore other ones.

So, the choice of didactic means for learning is made by teachers on the basis of:

- Classifying thinking by mental processes:

1) Visual-operatory (for babies under 18 months old);

2) Concrete-object (for kids from 18 months to 7 years old);

3) Abstract-logical (for kids 7 plus);

- thinking classification on the results of educational activities: 1) creative; 2) reproductive;

- thinking classification by the level of mental processes: 1) analytical; 2) intuitive.

According to the results of our surveys (334 respondents were questioned), teachers consider that bilingual students should develop all thinking operations (analysis, synthesis, comparing etc.) (94\%) (Lopatina et al., 2015), we should base on abstract-logical (43\%), visual-operatory (34\%), concrete-object (23\%) thinking. In other words, teachers often work with school students like with small kids, but it is impossible to achieve high quality in teaching bilingual students without these types of thinking use.

\subsection{Features of Axiological Approach Implementation}

Jerome Bruner (1954) considered thought as "translation" from one language into another. Bruner named 6 variants of this "translation": subject-image (practical), subject-iconic (humanitarian), subject-symbolic (operational), image-iconic (imaginative), image-symbolic (technical), iconic-symbolic (theoretical). So, he distinguishes the following factors of thought: practical - theoretical; humanitarian - technical; imaginative - operational; concrete - abstract. In other words, Jerome Bruner believed that image plays an important role in the process of thinking: he proposed three modes of representation: enactive, iconic, symbolic. At that, enactive and symbolic types refer to practical and technical content, but iconic type refers to imaginative content.

\subsection{Status of a Problem}

According to our surveys teachers say that they seldom care about creative thinking in mathematics and physics classes, concrete-abstract factor are meaningful in these classes ( $95 \%$ of respondents); humanitarian classes deny concrete thinking, abstract-operational factors are relevant there ( $87 \%$ of respondents). According to Bruner, teachers are mistaken, as image is included in both humanitarian and physical-mathematical content.

\subsection{Hypothesis}

Basing on contradiction we have formed a hypothesis, that a technology, which allows studying mathematics using both mathematical and creative thinking, the quality of education will not change for the worse (as teachers believe), but for the better.

\section{Materials and Methods}

\subsection{The Tasks of the Research}

In practice this technology was ordinary presentation of mathematical theoretic material (Poincare theorem or Lobachevsky conception, for example), but this presentation included:

1) Effective exciting stories about the creation and functioning of the conception;

2) Surprising examples from fiction, publicistic or popular-science literature;

3) Professional use of works of visual art (graphic, painting, sculptural arts) relevant to the topic.

\subsection{Theoretical and Empirical Methods}

The principle of the technology is to model a situation of "expectation of unexpected effect" (when a result of educational activities is "hooked" by student's mind and becomes his own) in formal mathematic content with the help of art and figurative means.

The only difficulty was to find common points of these didactic units (logico-mathematical and figurative-imaginative). The aim was to activate different types of thinking with the help of image and to test its influence on creativity, which is an essential quality characteristic of educating in the second language. We have carried out our test by the Jerome Bruner (1954) questionnaire. We diagnosed object thinking, symbolic thinking, iconic thinking, image thinking and defined creativity. 
By creativity we mean creative abilities of a student, who is ready to create brand new ideas. According to E. Torrance (1962) creativity involves hypersusceptibility to problems, knowledge shortage or contradictory; activity on defining the problems, on seeking the solution of the problems by hypothesizing, on verifying and changing the hypothesis, on formulating the decision result. To develop creative thinking we use training situations, which are defined by incompleteness or openness for new elements, and welcome many questions formulating.

We selected ordinary grades with students having both mathematical and humanitarian mind. Students having mathematical mind preferred symbolic thinking, they transformed information with the help of conclusions (particularly, algebraic rules or arithmetical signs and operations). It resulted in a thought expressed in structures and formulas, which established essential relationship between symbols. These students were $34 \%$ of all selected.

Students with humanitarian mind preferred iconic thinking. They transformed information by means of conclusions. It resulted in a thought in the form of idea or statement, establishing essential relationship between objects. These students were $42 \%$ of all selected.

Some students had pronounced visual thinking. Students with imaginative mind preferred image thinking. They transformed information by means of images operations. These operations were consequent as well as simultaneous. The result was a thought, materialized in a new image. These students were $24 \%$ of all selected.

\subsection{The Trial Infrastructure and Stages of the Research}

The level of creativity and base type of thinking was in three intervals according to Jerome Bruner (1954):

1) Low level (0 to 5 scores),

2) Mean level (6 to 9 ),

3) High level (10 to 15$)$.

\subsection{Experimental Procedure and Its Description}

In the first stage of our research we did the following:

1) Diagnosed creativity,

2) Organized experimental study according to the new technology.

\subsection{The Procedure and Results of the Experiment}

The experiment was carried out in 2008-2014 in ordinary grades of Zelenodolsk gymnasium No 3 and secondary school No10 (Tatarstan Republic).

856 students took part in the experiment.

The results of Jerome Bruner's test of creative thinking are presented in Table 1 and Table 2.

Table 1. The level of creativity and type of thinking before the experiment (the number of creative students in \%)

\begin{tabular}{llllllll}
\hline Grades & 5 & 6 & 7 & 8 & 9 & 10 & 11 \\
Low & 32 & 35 & 37 & 39 & 42 & 40 & 35 \\
Mean & 35 & 36 & 38 & 40 & 43 & 40 & 36 \\
High & 33 & 29 & 25 & 21 & 15 & 20 & 29 \\
\hline
\end{tabular}

Table 2. The level of creativity and type of thinking during the experiment (the number of creative students in \%)

\begin{tabular}{llllllll}
\hline Grades & 5 & 6 & 7 & 8 & 9 & 10 & 11 \\
Low & 21 & 20 & 18 & 15 & 12 & 10 & 7 \\
Mean & 33 & 31 & 29 & 25 & 23 & 19 & 16 \\
High & 46 & 49 & 53 & 60 & 65 & 71 & 77 \\
\hline
\end{tabular}

We see that image thinking activation in mathematics classes lets not only learn the material better, but also show creative attitude to it: students demonstrated their knowledge, were interested in using the theoretical material in 
practice, suggested interesting hypotheses and original ideas.

\subsection{Evaluation Criteria}

All the changes were recorded in progress from 5 th to 11 th grade.

Before the experiment (see Table) 1) the quality of education didn't change dramatically: about one third of students (except for 7, 8, 9 grades) demonstrated either low or mean or high level of creativity. Only in 7th, 8th and 9th grades (awkward age) the number of kids with high level of creativity reduced substantially (from $25 \%$ to $15 \%)$.

During the experiment the situation was changing dramatically: Low level decreased steadily (from 21 to $7 \%$ ), mean level also decreased (from 33 to 16\%), but high level constantly increased (from 46 to $77 \%$ ).

\subsection{Experimental Procedure and Its Description}

In the 2nd stage we studied intellect, theoretical and practical abilities of the students. We used Amthauer test IST (1961) for this purpose. Amthauer R. (1961) considered intellect to be a special sub-structure in a personality entire structure, which consists of different factors (verbal, numerical, spatial representation, mnemic). The test measures verbal, numerical, figural and mnemic intelligence. The correlation between these factors, 3 of which are similar to Spearman's factors (1950), equals 0.36. The time taken for the test is 90 minutes.

\subsection{Evaluation Criteria}

Amthauer test (1961) includes 9 subtests. All subtests except for No 4, 5 and 6 have enclosed-type tasks:

1) Sentence Completion (SC) - tests linguistic intuition (the task was to choose (from the given alternatives) the word that correctly completes the sentence;

2) General Evidence (GE) - tests the ability to find notional abstraction (the task was to choose the word (from five given alternatives) which didn't have notional relationship with the others;

3) Analogies (AN) - tests student's combinatorical abilities. The respondent must identify the relationship between two words and then apply the rule governing the relationship by finding a word that shows a similar relationship to another given word;

4) Classification (CL) - tests the ability for reasoning (the task was to find a common collective term for two words;

5) Calculations (CA) - tests the level of the student's arithmetic reasoning (the respondent must do 20 sums);

6) Number Series (NS) - tests inductive reasoning (the task is to determine the rule for each series and to find the next number in the series);

7) Figure Selection (FS) - tests spatial perception. Some pieces resulting from cutting up one of the shapes are shown. The task was to identify which of the whole shapes can be produced by fitting together the pieces;

8) Cubes (CU) - tests the respondent's ability to move mentally tridimensional bodies in space (a picture of cube is presented after it has been rotated through space. The task is to identify which cube has been rotated);

9) tests concentration and memory (ME) (the respondent must memorize words series and find them among others).

Each correct answer added one point (except for subtest4). The obtained score was transfered into scale. Then aggregation of obtained score in all the subtests made overall assessment of intelligence level.

Amthauer (1961) supposed that if the first four subtests give the highest results, then a respondent have academic abilities. If the last five subtests give the highest results, then a respondent have practical abilities.

Test-retest reliability (repeated testing in a year's time) is $0.83-0.9$. Parallel-form reliability is 0.95 . The correlation with academic progress, according to Amthauer's data is 0.46 , with expert estimation of intelligence level is 0.62 .

The results of the level of theoretical and practical abilities testing (before and during the experiment) are presented in Tables 3 and 4 . 
Table 3. The students' level of theoretical and practical abilities before the experiment (percentage)

\begin{tabular}{llllllll}
\hline Grades & 5 & 6 & 7 & 8 & 9 & 10 & 11 \\
Theoretical & 22 & 34 & 31 & 21 & 27 & 28 & 25 \\
Practical & 45 & 48 & 54 & 61 & 58 & 60 & 65 \\
$\begin{array}{l}\text { Haven't } \\
\text { demonstrated }\end{array}$ & 23 & 18 & 15 & 18 & 15 & 12 & 10 \\
\hline
\end{tabular}

Table 4. The students' level of theoretical and practical abilities during the experiment (percentage)

\begin{tabular}{llllllll}
\hline Grades & 5 & 6 & 7 & 8 & 9 & 10 & 11 \\
Theoretical & 35 & 38 & 43 & 47 & 51 & 56 & 62 \\
Practical & 62 & 58 & 52 & 48 & 46 & 41 & 46 \\
$\begin{array}{l}\text { Haven't } \\
\text { demonstrated }\end{array}$ & 3 & 4 & 5 & 5 & 3 & 3 & 2 \\
\hline
\end{tabular}

\section{Results}

As we can see, before the experiment the level of theoretical abilities didn't tend to grow and was about from 22 to $25 \%$ and the level of practical abilities was slightly growing (from 45 to $65 \%$ ) (see Table 3 ) but during the experiment the level of theoretical abilities of 5th year students was $35 \%$ and of 11 th year students increased to $62 \%$; the level of practical abilities increased from $45 \%$ (see Table 3) to $62 \%$ (see Table 4). And it slightly decreased by the 11 th year $-46 \%$ (see Table 4 ).

The following subtests were used for examining the connection between general mental abilities and students' professional interests: "verbal thinking", "numeric abilities", "technical thinking", "abstract thinking", "spacial relation". We identified that aptitude to "person-person" professions negatively correlate with general intellect (r $=-0.40)$ and the level of technical thinking $(r=-0.30)$. At the same time the level of general intellect positively correlate with interest to physics and mathematics $(0.31 ; 0.34)$.

\section{Discussions}

Usually when teaching in the second language, all teachers try to pay more attention to semantization (translation, explaining) of unknown words. We didn't do it during our research. But students understood not only words, but also sentenses, texts, humor, wonder, pleasance which were expressed by the teacher. The question of necessity to introduce words interpretation is poorly studied in teaching physics and mathematics. We believe that vocabulary work will break the emotional state of the lesson, when students are involved in the teacher's wonderful imaginative story and acquire information in a different way.

There are many techniques in foreign languages teaching methodology including ones with words interpretation and without it (the method of immersion to cultural background of the language) etc. But not all of these techniques can be used in physics and mathematics teaching as these subjects need not only learning the language, but also learning the theory. Our method allows learning the second language (Russian), which was a wonderful mathematics and physics language.

We still have a question to discuss if students with humanitarian thinking can become good mathematicians or physicists. Our research shows that about $30 \%$ of them can develop their powers in mathematics or physics.

\section{Conclusion}

Our research proves the hypothesis that creative thinking activation in physics and mathematics lessons has positive influence on the quality of education - on the second (Russian) language learning, physics and mathematics theory, students' academic thinking and creative abilities development. We also noticed that the students who had disliked physics and mathematics and had believed they have humanitarian thinking showed special interest for these subject. Some of them even changed their preferences for the subjects.

\section{Acknowledgments}

The work is performed according to the Russian Government Program of Competitive Growth of Kazan Federal University 


\section{References}

Amthauer, R. (1961). Intelligenz und Beruf. Amthauer R. Zum Problem der produktiven Begabung. In Prelinguistic to Linguistic Communication (pp. 27-42). Hillsdale, NJ: Lawrence Erlbaum Associates.

Biktagirova, G. F., \& Valeeva, R. A. (2014). Development of the teachers' pedagogical reflection. Life Science Journal, $11(9), 60$.

Bruner, J. (1995). From joint attention to the meeting of minds. In C. Moore, \& P. Dunham (Eds.), Joint Attention: Its Origins and Role in Development. Hillsdale, N.J.: Erlbaum.

Bruner, J. S. (1983). The acquisition of pragmatic commitments. Thinking. N.Y.

Bruner, J. B., \& Tagiury, R. (1954). The perception of people. Handbook of social psychology: Reading (Mass), $2,9-41$.

Ivanenko, N. A., Akhmetov, L. G., Lavrentiev, S. Y., Kartashova, E. P., Lezhnina, L. V., Tzaregorodtzeva, K. A., \& Khairullina, E. R. (2015) Features of Modeling the Formation of Teaching Staff Competitiveness. Review of European Studies, 7(3), 37-42. http://dx.doi.org/10.5539/res.v7n3p37

Ivanov, V. G., Shaidullina A. R., Drovnikov A. S., Yakovlev S. A., \& Masalimova, A. R. (2015). Regional Experience of Students' Innovative and Entrepreneurial Competence Forming. Asian Social Science, 11(1), $35-40$.

Kalimullin, A. M., \& Gabdilkhakov, V. F. (2014). Tutoring of pedagogical activity and new ideology of teacher training in the higher education institution. Life Science Journal, 11(11), 183-187.

Levina, E. Y., Akhmetov L. G., Latipova L. N., Mirzagitova A. L., Mirzanagimova F. I., Latipov Z. A., \& Masalimova, A. R. (2015). Diagnostics of Educational Activity Quality on the Basis of Qualitative Methods. Asian Social Science, 11(4), 246-251.

Lisitzina, T. B., Nikonov, V. V., Ilkevich, K. B., Ilkevich, T. G., \& Masalimova, A. R. (2015). The Syllabus of the Regional Component of Professionally Motivational Education Developed for the Students Specializing in Tourism. Asian Social Science, 11(2), 284-289.

Lopatina, O. V., Borisov, A. M., Leyfa, I. I., Galimzyanova, I. I., Yatsevich, L. P., Demyanenko, M. A., \& Masalimova, A. R. (2015). Role of foreign language teacher shaping students' research skills. Asian Social Science, 11(4), 135.

Lopatina, O. V., Fassakhova, G. R., Akhmetova, L. A., Gatin, R. G., Yarullina, A. S., Nikishina, S. R. \& Khairullina, E. R. (2015). The Technology of Forming the Students' Research Competence in the Process of Learning a Foreign Language. Asian Social Science, 11(3), 152-157.

Rubinstein, S. L. (1989). Psychology. M.

Sakhieva, R. G., Ibatullin, R. R., Biktemirova, M. K., Valeyeva, G. K., Pchelina, O. V., Valeyeva, N. Sh., Minsabirova, V. N., \& Khairullina, E. R. (2015). The Essential, Objective and Functional Characteristics of the Students' Academic Mobility in Higher Education. Review of European Studies, 7(3), 335-340. http://dx.doi.org/10.5539/res.v7n3p335

Shaidullina, A. R., Fassakhova, G. R., Valeyeva, G. K., Khasanova, G. B., Komelina, V. A., \& Ivanova, T. L. (2015). A Comparative Research on Levels of Students' Formation Skills of Their Career Advancement Portfolio in Secondary and Higher Education Systems. Asian Social Science, 11(1), 375-379.

Spearman, C. (1950). Human Ability. Macmillan, London.

Strategy of long-term social and economic development of Russia until 2020. (2008). Russian Federation Government Executive Order dated November, 17, 2008.

Torkunova, J. V., Khairullina, E. R., Komelina, V. A., Volkova, N. V., \& Ponomarev, K. N. (2014). The Peculiarities of Qualitative Information, Analytical Maintenance Innovative and Educational Activity Technological Projection in Higher Educational Institution. Life Science Journal, 11(8s), 498-503. Retrieved from http://www.lifesciencesite.com

Torrance, E. P. (1962). Developing creative thinking through school experience. In S. J. Parnes, \& H. F. A. Harding (Eds.), Source Book of creative Thinking. N.Y.

Valerian, F. G. (2011). Of linguistic education in kindergartens. International Journal of Early Years Education, $19(2), 185-188$. 
Valerian, F. G. (2014a). Personification of Multicultural Education in the Universities of Russia (Analysis of Training Specialists for Kindergartens). Procedia-Social and Behavioral Sciences, 146(25), 129-133.

Valerian, F. G. (2014b). Multicultural Language Development of Preschool Children in Russia Procedia-Social and Behavioral Sciences, 146, 222-225.

Valerian F. G.' (2014c). Communicative Core of Interaction and its Influence on Education Results. Procedia-Social and Behavioral Sciences, 146, 381-384.

Valeeva, R. A., Koroleva, N. E., \& Sakhapova, F. K. (2015). Civic education of the technical university students in foreign language classes. Review of European Studies, 7(1), 176-180.

Valeeva, L. A., \& Valeeva, R. A. (2013). Development of future engineers' critical thinking in foreign language teaching (p. 438). In 2013 International Conference on Interactive Collaborative Learning. ICL.

Vlasova V. K., Kirilova G. I., \& Masalimova, A. R. (2015). Information and Logistic Foundations of Pedagogical Education Design and Content Education. Review of European Studies, 4(7), 54-58. http://dx.doi.org/10.5539/res.v7n4p54

\section{Copyrights}

Copyright for this article is retained by the author(s), with first publication rights granted to the journal. This is an open-access article distributed under the terms and conditions of the Creative Commons Attribution license (http://creativecommons.org/licenses/by/3.0/). 